\title{
Study on Service-oriented Manufacturing of Aviation Equipment Industry *
}

\author{
Liangqing Feng ${ }^{1}$, Dali Huang ${ }^{2}$ and Chao Xia ${ }^{3}$ \\ ${ }^{1}$ School of Economic and Management Nanchang Hangkong University Nanchang, Jiangxi Province, China \\ ${ }^{2}$ School of Economic and Management Nanchang Hangkong University Nanchang, Jiangxi Province, China \\ ${ }^{3}$ School of Economic and Management Nanchang Hangkong University Nanchang, Jiangxi Province, China \\ flq9848@163.com, zziahll@126.com, xiachaozzia@163.com
}

\begin{abstract}
Under the background of service economy, with the integrative development of the manufacturing and services, the service-oriented manufacturing emerges as the times require. The high-end equipment industry is an important measuring standard for the level of manufacturing industry development, whose transition to the industries service is the great significance to improve the comprehensive national strength. Took the aviation equipment industry as study background, this paper explored how to build the service-oriented manufacturing model in the aviation equipment industry. Firstly, the value space of aviation equipment industry was analyzed, then combining with the value chain, it analyzed how to create the value of aviation equipment industry, and it put forward two organization modes and three development strategies for the aviation equipment industry to put the service-oriented manufacturing model to use, finally, this paper illustrated the practice of the service-oriented manufacturing model in the aviation equipment industry by the Boeing company.

Keywords-Aviation equipment industry; Service-oriented manufacturing; Modular Service.
\end{abstract}

\section{INTRODUCTION}

The aviation equipment industry plays an important role in the field of military and economic. Most countries define aviation industry as a national strategic industry, which is not only an important basis of national defence security, but also reflects the degree of the industrial development of a country and reflects the national comprehensive power. The characteristics of aviation products are as follows: high value per unit, complex structure, high technology content and a long industrial chain structure. So, to make the service industry and manufacturing integrate together, complete the upgrade of industrial structure has an important significance. Some Scholastics (G. Li \&L. Sun, 2009; W. Lin \&Z. Jiang, 2009) have elaborated the origin, concept and value creation mechanism of the service-oriented manufacturing and have further studied the service mechanism of "production system", which laid a solid theoretical basis for the aviation equipment industry to implement the service-oriented manufacturing mode. The value of service-oriented manufacturing complies with the "smile curve"; the value space exited in each link of the service-oriented manufacturing value chain is the key for equipment industry to get profits. Many scholars have reconstructed and optimized the service-oriented manufacturing value chain $(\mathrm{H}$. Hu, 2004; C. Yang \& Y. Ming, 2008; Z. Ding \& Q. Jin, 2013; H. Li, 2012; X. Li and P. Wang, 2011 ), have provided a theoretical support for the transformation and development from the traditional manufacturing to the service-oriented manufacturing mode. About the service-oriented manufacturing model, Y. Wang \& Y. Fei (2011) put forward the industrial technology innovation alliance strategy, and by taking high-end equipment industry as the research background, they expounded the effectiveness of the industrial technology innovation alliance organization mode to the high-end equipment industry. For the serviceoriented manufacturing strategies, X. Zhu \& Y. He (2011) came up with a service-oriented extension strategy and they took Shaanxi Gu as an example to validate the feasibility of this thought. The current researches on aviation equipment industry particularly focus on the status and countermeasure, however, there are few studies aim to the service-oriented manufacturing development, besides, the present research is a little scattered, still not consist of a complete system. Based on taking aviation equipment industry as a background, this paper systematically introduced its mechanism of the serviceoriented manufacturing, organization patterns and strategies research; on the other hand, this paper put the module thought in it, provided a new way of thought as a reference for the development of aviation equipment industry.

\section{The Value SPace of Aviation Equipment MANUFACTURING BY SERVICE-ORIENTED MANUFACTURING}

\section{A. Reasons for the Formation and Mechanism of Service- oriented Manufacturing}

For almost a century, with the progress of scientific and technological and the evolution of industrial policy and the rapid changes of market demand and economic development, the manufacturing models have changed a lot, a series of advanced manufacturing patterns appeared, such as the mass customization, flexible manufacturing,

\footnotetext{
* This work is partially supported by National Natural Science Foundation of China Grant \#71362019 and Jiangxi Provincial Academy of social sciences pl an project Grant \#12GL24.
} 
JIT production, LP, CIMS production and agile manufacturing etc. While, these manufacturing modes commonly achieve value-added by physical products, less attention to the services; they emphasize integration and optimization of manufacturing resources on operation model, lack of the focus on the interaction of the agglomeration and collaborative about enterprise module unit. Since the late 20th century, the Proportion of manufacturing industry in the national economy continued to decline in the western developed countries; conversely, the proportion of service industry gradually raised, as a result, the transition from industrial economy era to the post-industrial of economic structure was gradually completed.

As the enhancement of industrial clustering and competitiveness, the service-oriented manufacturing arises at the historic moment. Under the background of economic globalization, because of the continuous development of science and technology and the diversification of customer demand, the service-oriented manufacturing emerges as a new manufacturing mode, which put the manufacturing and services together, obscures the line between services and manufacturing. As a new manufacturing mode, in the present industrial development, most managers have made more and more attention on it, a typical manifestation about the manufacturing mode is the transition from traditional manufacturing to provide product service system and the transition of the total solutions. Specifically to say, by providing "product + services" to the customers through integrating tangible physical products and intangible value services, of course, it is possible for the manufacturing industries to achieve value-added of value chain, both internal and external chain, and achieve the aim of improving enterprise competitive advantage.

From the perspective of the organizational structures of service-oriented manufacturing, mostly they are chains and meshes, which are the net chains structure, connected by multiple nodes between enterprises or departments. This paper defined the service-oriented manufacturing organization structure as a mesh structure that composed with three types of module nodes: the productive service module, service production module and customer utility module (L. Feng, 2012). As shown in Fig.1.

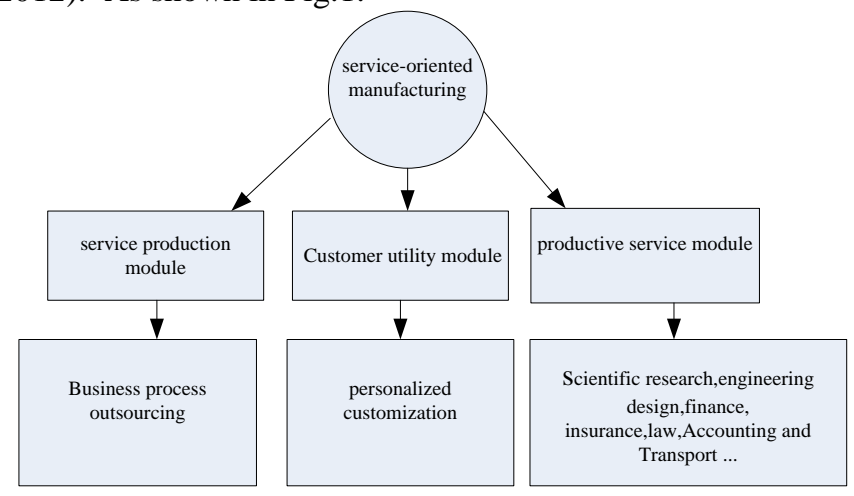

Fig. 1 The structure of service-oriented manufacturing.
By optimizing and integrating the diversified manufacturing and services, making the three aspects (productive service, service production and customer utility) to operate cooperatively, letting the services as a carrier of communication between participants of the value chain, the service-oriented manufacturing can bring huge economic benefits to the enterprises. The construction of service-oriented manufacturing is helpful for the change of domestic economic growth pattern, which can promote China's manufacturing industry to upgrade, and can enhance the competitiveness of the enterprises.

\section{B. The Global Value Chain Structure of Aviation} Equipment Industry by Service-oriented Manufacturing

The traditional value chain generally just involves the manufacturing process of material products, value-added is considered as to be achieved only through a lot of product assembly and manufacturing technology, the value chain is divided to three parts: upstream, midstream and downstream $(\mathrm{H}$. Hu, 2004). With the rise of the service business, the value-added link of the value chain is becoming more and more and the structure is more complex than before.

For the service-oriented manufacturing, whose valuecreation process has a close relationship with customers, so constructing a service-oriented manufacturing value chain facing to customers will become the essential part for the transformation from the traditional manufacturing to the service-oriented manufacturing. The value chain model of the service-oriented manufacturing can be summarized as "three full modes" (Daniel bell, 1986): full cycle service, full participation and full meet the demand. Development, parts manufacturing, equipment, sales and services are the world's five processes of the aviation equipment industry's value chain. The Service-oriented manufacturing mode makes the traditional value chain get extension from vertical and horizontal, let the services extend to every link of the value chain (Fig. 2), which is more advantageous to realize the value-added of the value chain.

From the perspective of value chain, service-oriented manufacturing mode could change the way of traditional value-added, increase the value-added links and make the whole value chain become the polymer of the value. 


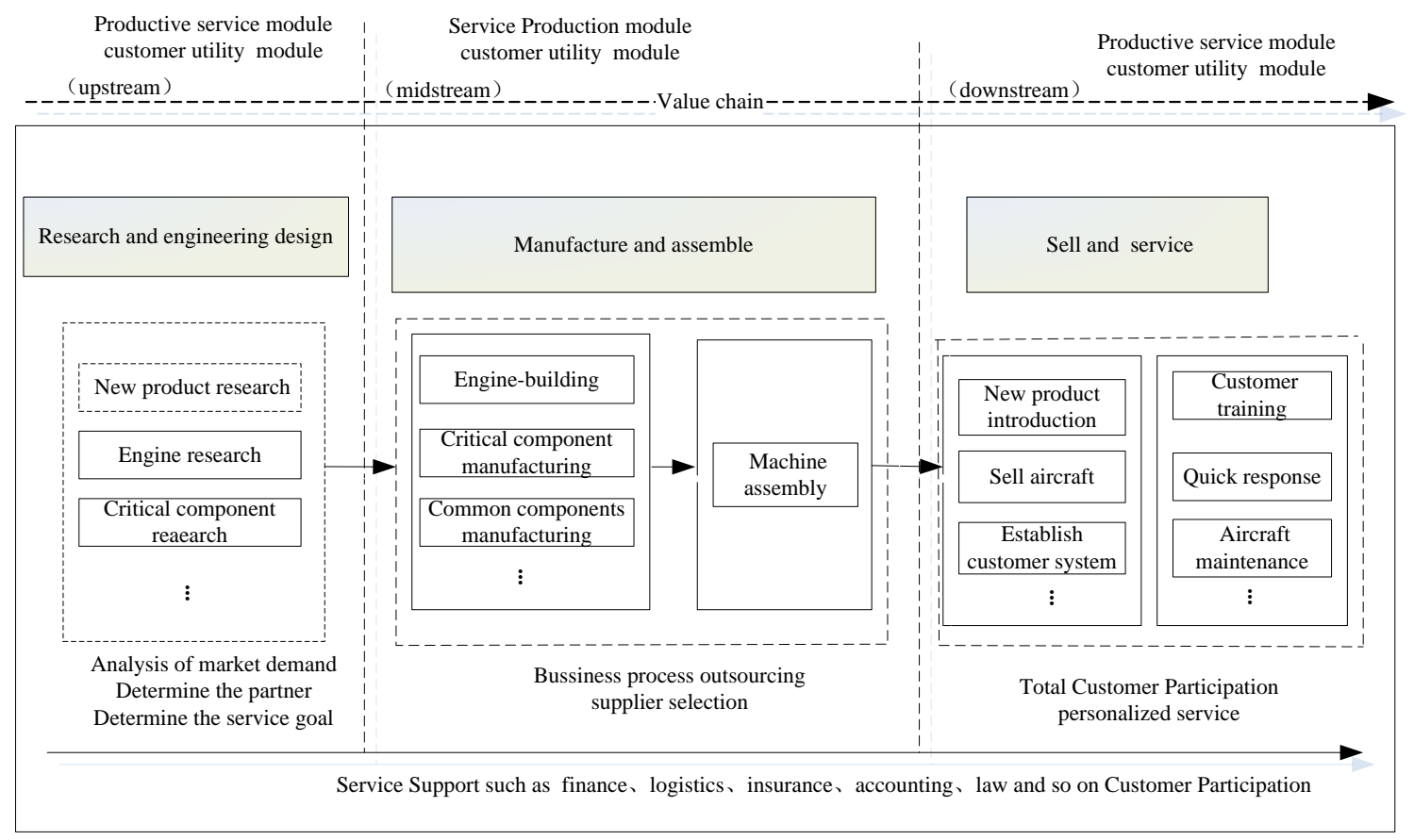

Fig. 2 The global value chain structure of aviation equipment industry.

\section{The Value Creation of Aviation Equipment Industry by Service-oriented Manufacturing}

The value creation tend to be described as a series of business activities such as the enterprise production and the supply that in order to meet the target customer's demands for the products and services. Aviation equipment products have these characters as follows: high value content, intensive technology content and high raw material requirements, so to enhance the value creation of aviation equipment industry is of great significance. From the value chain structure (Fig. 1) and the Stan shih's smile curve (Fig. 3), it is easy to reach the conclusion that, the upstream and downstream of the value chain (the product research and development and after-sale service) are the two parts which have more additional value, therefore aviation equipment industry should strengthen the research and development, the technical design, brand marketing and service ability to improve the ability of value creation.

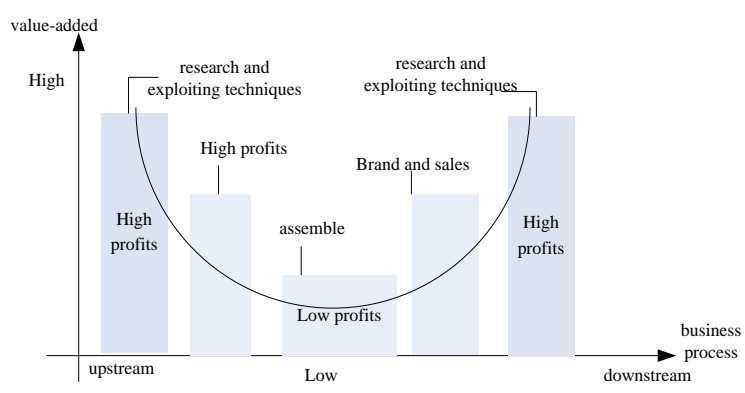

Fig. 3 Smile curve.

With the service-oriented manufacturing pattern, the enterprise can achieve more resource value creation, customer value creation, green value creation and service value creation through the integration of internal and external resources and the business process modular services. As shown in Fig. 4. 


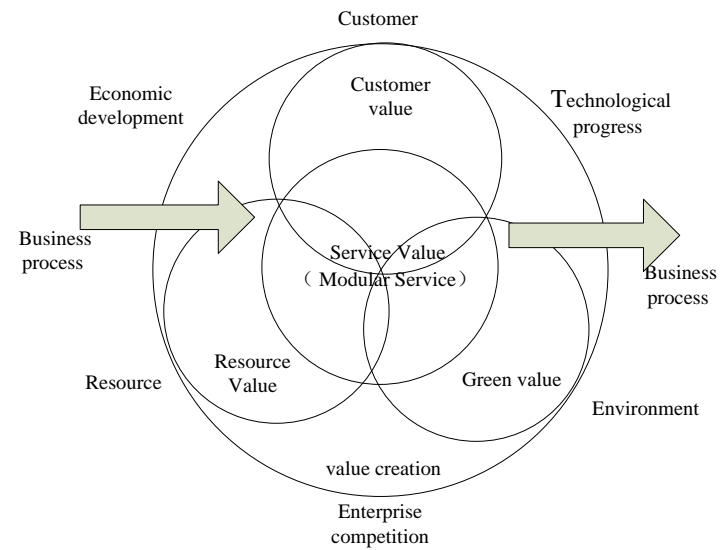

Fig. 4 Value creation of service-oriented manufacturing.

Following the rule of the integrated mode of "product + services", the aviation equipment industry, through the way, that let the air leading enterprise control and manage other services groups and make each module share the resources and information together by the service integration nodes, can reduce enterprises management costs and the marginal cost of the products, of course it is very beneficial in improving the resource value creation. With the service-oriented manufacturing mode, by setting up special aviation services departments, the aviation equipment enterprises can improve the speed of responding to customer requirements and opinions, and improve and modify the products in timely, which is helpful to promote the product innovation, brand influence and customer satisfaction, also, is helpful to improve the customer value creation. Low carbon product service system is a global advocacy task, for aviation enterprise; to produce high fuel efficiency, low emissions and low noise environmental protection model will certainly improve the competitiveness of products. From that perspective, the environmental protection consciousness of the service-oriented manufacturing plays a positive role in improving the green value creation.

\section{The ORgANIZATION MODE OF AVIATION EQUIPMENT INDUSTRY BY SERVICE-ORIENTED MANUFACTURING}

\section{A. The Service-oriented Manufacturing Network}

With the driving of service demands and service ability, as the development of manufacturing and services integration, the service-oriented manufacturing network (SMN) appeared, which is a network composed of the manufacturing enterprises, the relevant departments and personnel of services enterprises and the customers. The composition of SMN mainly includes the participation of customers, manufacturers and service enterprises. Through the establishment of the SMN system, it can provide more effective products and services to enterprises; also can realize the maximization of economic, social and environmental benefits.

Each subject of SMN is integrated by the network nodes. The SMN model of the aviation equipment industry belongs to the leading enterprise integration pattern, that is, by small and medium-sized enterprises providing the manufacturing processes and service processes supporting to the large enterprises, cooperating with large enterprises to achieve these activities : product research, processing, assemble and sales of products. With the four modules, the service production module node (the service provider providing manufacturing service), the productive service module node (the service provider providing service producer), the customer utility module node (customer participation) and the service integration module node (the service module integrator integrating the three modules), by this way, the aviation equipment industry build a service-oriented manufacturing network.

In practice, the enterprise shall carry out specific analysis on the behaviour main body of SMN, find out the main factors that influence the various modules and make the various modules collaborative operation, to realize the optimal integration of the resources in the network.

\section{B. The Technology Innovation Alliance}

The industrial technology innovation alliance strategy is to point to a Technology innovation cooperation organization formed by the enterprises, universities, research institutions and other organizations, which based on enterprise's development needs and the common interests of the parties, aims for promote industrial technology innovation ability and regards a legally binding contract as the security, and the technology innovation alliance has the characteristics like the joint development, complementary advantages, benefit-sharing and risk-sharing. That strategy is the important carrier of the implementing technology innovation project for the national.

The aviation equipment industry is a high-end equipment manufacturing industry. Through the transformation of the traditional manufacturing mode by the high and new technology and advanced applicable technology, the creation of the technology innovation alliance, which combined with equipment manufacturing enterprises, universities, research institutions and other organizations, consisted of "production, study and research, is beneficial in integrating resources advantages, is conducive to form a industry value chain of operating efficiently and enhance the comprehensive competitiveness of the aviation equipment industry. At present, there are two main types of alliance suitable modes for high-end equipment industry to implement the technology innovation alliance: the alliance of contracts pattern and entity type alliance. The first is based on the members of party autonomy, the union is more flexible, but the structure is loose, it is difficult to establish an efficient operation mechanism and effective coordination mechanism; while the alliance agreement nature of the last belongs to civil contract, the agreement content is 
determined by the coalition parties themselves completely, therefore, it is a more stable alliance.

The purpose of alliance is to combine their own core competence advantage and to seek joint synergies. The development of the industrial technology innovation alliance is not only influenced by the internal factors such as government, universities and research institutions, but also influenced by political, economic, culture and other external factors. When choosing a partner, aviation equipment industry should have a multi-angle analysis and comprehensive consideration, and then choose the right allied partner and the suitable type.

\section{DEVELOPMENT STRATEGIES OF SERVICE-ORIENTED MANUFACTURING ABOUT AVIATION EQUIPMENT INDUSTRY}

\section{A. The Strategy of Modular Service Extension}

In order to provide more high-quality aviation services, aviation equipment industry should use the modular service extension strategy. The modular service extension mainly refers to the service-oriented manufacturing enterprises permeate into the productive services, namely, whose business modules permeate into the productive service value modules, form separate organizational units and become the provider of service module. At this time, the module providers coordinate with module service providers, try to maximize the interests.

The aviation equipment industry to implement the modular service strategy is to extend the services to each link of the production, embed the service to the value-added networks and realize the integration of manufacturing service module. For example, the productive service providers extending to productive service modules mainly include the financial companies, public service groups, aviation services and trade company, which provide the productive service support for the manufacturing. Through the modular services extension, the flexibility and convenience of manufacturing business processes can be improved; on the other hand, through the modular service extension, it is beneficial for aviation equipment enterprises to expand business scope such as the aviation leasing, maintenance services, navigation operations and the market development, which will strengthen the competitiveness of the enterprises.

\section{B. The Strategy of Modular Service Outsourcing}

The modular service outsourcing of the aviation equipment industry, is mainly refers to the process outsourcing of service production module and the outsourcing of the productive service module. By the service production modular outsourcing mode, aviation equipment industry could reduce the link between the sub-modules and the coordination cost. In the outsourcing of parts production and assembly processes, aviation equipment enterprises should consider the main ability mainly includes: the processing equipment ability, the number of the processing networks, advanced technology level, mass production of flexible ability and the return ability on service innovation. The productive services outsourcing mainly include the outsourcing of the information technology, business process and knowledge process.

The distribution law of value-added of the Service outsourcing industry chain conforms to the principle of "smiling curve": the largest outsourcing service provider is located in the most high-end chain. With the industrialization of the modular outsourcing services such as the capacity improvement of international subcontracting production, the industrialization of new materials and components, it is advantageous for the aviation equipment enterprises to enhance the core competitiveness of the product, also, is helpful to enhance human capital accumulation and to play a role of economies of scale.

\section{The Integration of Modular Service}

By the support of information technology, the integration of the modular service is formed with the integration of facilities and services technology and management, which is a modular service network, whose interior is closely connected each other and operate efficiently.

In the service-oriented manufacturing network, the modular service makes the module integration become inevitable. According to the specific requirements given by their own enterprises, cooperative enterprises and customer, through the industrialization of the module service integration, such as promoting the ARJ21, the serial development of Xinzhou regional aircraft. The service module integrators with integrated advantages could enhance the aviation parts level and the internationalization of airborne systems development level. The connection between the modules is based on the market, while the market is temporary and fluid, however, the modular service integrators can adjust various modules in timely according to the different technical environment and market dynamics, making it become possible for the various modules of service-oriented manufacturing network providers to get the most benefits.

\section{CASE AnAlysis: THE SERVICE-ORIENTED MANUFACTURING MODEL OF BOEING}

Founded in 1916, as the largest manufacturer of civil and military aircraft, adhering to the fine tradition of innovation, the Boeing Company is a typical representative in the aerospace field who has implemented the service-oriented manufacturing model. Following the integration pattern of "product + services" (as shown in Fig. 5), Boeing has always centered on aircraft carriers and passengers and tried to continuously meet the needs of customers. In the service-oriented manufacturing network, Boeing assumes the main part of the leading enterprises, who is not only the manufacturing module integrator, but also the service module integrator. 


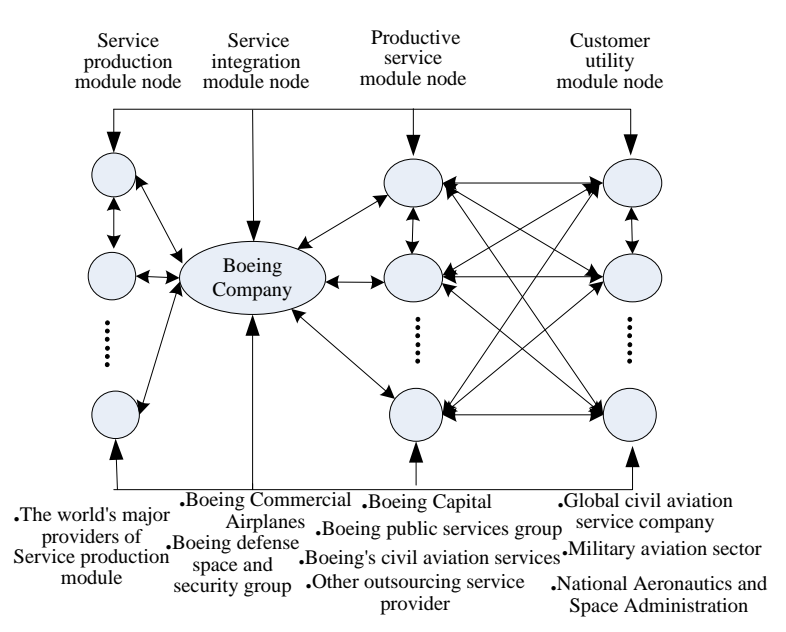

Fig.5 The model structure diagram of Boeing's service-oriented manufacturing.

As the important service provider of NASA's space shuttle and the operation service provider of the international space station, during the processes of value creation, Boeing emphasizes to provide the rich connotation of the service product to customers and pay more attention to increase the resources value creation and the customer value creation. Boeing has applied for a large number of invention patents; it also can prove that, the company is good at innovation, which is beneficial to enhance the value creation of upstream and downstream in the industry value chain.

To provide better air services, Boeing has implemented the modular service extension strategy, whose main supplier of the productive service module includes Boeing financial services company, Shared services group, civil aviation service and Boeing aircraft trading company and so on. In addition, the Boeing Company has adopted the modular outsourcing strategy in the whole world and realized the globalization of production, various models of many system modules are outsourced to service production module providers, which is distributed in all around the world. Providers of the various modules are distributed as many as 66 countries. Generally, the module providers can be mainly divided into two categories: module providers directly and module providers indirectly. The module providers directly are mostly responsible for the research and development of the aircraft subsystem, typically they have a certain competitive power and core competence advantages to aviation manufacturing enterprises, whose distribution mainly concentrate in the United States, France, Canada, Spain, Germany, China, Italy, the Middle East, India, South Korea, Japan and other countries or regions; while, the module providers indirectly are mainly responsible for the research and development and production of the spare parts.

In the latest development of new aircrafts, Boeing has put forward the new requirements of integrated effects to module providers, that is: module providers should not only provide module outsourcing production, but also the innovation reform of the module quality and provide the system integration of relevant modules. Thus, the Boeing not only can reduce the investment risk, also can strengthen the information communication and technology transfer of the module providers and can improve the service quality level. As the world's giant on aviation manufacturing domain, at present, Boeing has formed the modular integrated strategic alliance with many aviation manufacturing enterprises including Europe and the United States, which makes each other play a role of Modular coordination quality according to their own core competence and competitive advantage.

\section{CONCLUSION}

Based on the special industry, aviation equipment industry, this paper studied the service-oriented manufacturing and described the value space of the aviation equipment industry by establishing a value chain. About the service-oriented manufacturing mode, this paper holds the opinions as follows: the aviation equipment industry will get more value-added with the service-oriented manufacturing network mode and the technology innovation alliance mode. This paper put forward three strategies (the modular service extension, modular service outsourcing and modular service integration) to make the aviation equipment manufacturing can implement the service-oriented manufacturing mode. Finally, this paper illustrated the service-oriented manufacturing mode of the Boeing Company, whose purpose is to provide a reference for aviation equipment manufacturing industry to implement the service-oriented manufacturing production.

\section{ACKNOWLEDGMENT}

This paper is one of periodic achievements of the following two projects: funded by the National Natural Science Foundation of China, "study on quality control of service-oriented manufacturing network based on the behavioural measurement "(71362019), and the Jiangxi Provincial Academy of social sciences plan project, "study on service-oriented manufacturing model and comprehensive synergy innovation of aviation strategic emerging industries" (12 GL24).

\section{REFERENCES}

[1] G. Li and L. Sun, "Service-oriented manufacturing's origin, concept and value creation mechanism," Science and Technology Progress and Measure, 2009, Vol. 26, pp. 0068-0070.

[2] W. Lin and Z. Jiang, "reserach overview of the Service-oriented manufacturing theroy," Industrial Engineering and Management, 2009, Vol. 14, pp. 0001-0006.

[3] H. Hu, "Reengineering of the global manufacturing value chain and China strategic choice," Science and Technology Progress and Measure, 2004, Vol. 21, pp. 43-47. 
[4] C. Yang and Y. Ming, "Producer services and analysis on changes of manufacturing value chain," Computer Integr ated M anufacturing Sy stems, 2008, Vol. 14, pp. 0153-0160.

[5] Z. Ding and Q. Jin, "On Value Creation of Service Manufacturing Companies," 2013, Vol. 5, pp. 91-94.

[6] H. Li. "Research on the Mode and Path of Aviation Manufacturing Servitization in Jiangxi Province," Nanchang: Nanchang University, 2012, pp. 40-48.

[7] X. Li and P, "Wang Study on Value Network of Civil Aircraft Based on Service -on Oriented Manufacturing," Aeronautical Science and Technology, 2011, Vol. 6, pp. 48-50.
[8] Y. Wang and Y. Fei, " research of the Industrial technology innovation alliance organization pattern : for High-end equipment manufacturing industry," Science and Technology Progress and Measure, 2011, Vol. 28, pp. 0070-0074.

[9] X. Zhu and Y. He, "Transitional Process from Manufacturer to Service Provider and Capability Development," A Case Study of Shangu Co. Chinese Journal of Management. 2011, Vol. 8, pp. 0356-0454.

[10] L. Feng, "The quality behavior research of service-oriented manufacturing network node", economic science press, Beijing, 2012, pp. 22-178 